\title{
Percutaneous nephrolithotomy in children
}

P Singh, R Kumar

\author{
All India Institute of Medical Sciences, New Delhi, India
}

Key words: renal calculi, paediatric, percutaneous nephrolithotomy.

\begin{abstract}
The incidence of stone disease in the paediatric population varies throughout the world. Paediatric urolithiasis may be associated with underlying metabolic/enzymatic or anatomical abnormalities, which should be corrected simultaneously with the stone management. Children have soft and mobile kidneys, flexible ureter, and smaller urinary tract with narrow working space requiring smaller endoscopic instruments. Introduction of percutaneous nephrolithotomy (PCNL) revolutionized the treatment of large upper tract stones. Innovations, miniaturization of instruments, refinements in endourological techniques made PCNL in children safer and efficient and paved the way for this procedure to be accepted as a standard for large upper tract stones. We searched the Medline ${ }^{\circledR}$ and Pubmed ${ }^{\circledR}$ databases using the search terms 'paediatric, percutaneous nephrolithotomy, stones, and complications' for articles published between the years 1990 and 2012. More than 40 articles related to this topic were retrieved and reviewed and are presented in this review.
\end{abstract}

\section{Introduction}

There has been an increase in the incidence of stone disease in the paediatric population, possibly because of a change in dietary habits and life style. Diets rich in sodium and carbohydrates may be the one of the contributing factor for stone disease $[1,2]$. Incidence of stone disease in pediatric population varies from 5 $15 \%$ in developing countries to $1-5 \%$ in developed countries [3]. Stone management in children has specific issues, they may be associated with underlying metabolic/enzymatic or anatomical abnormalities which increase stone recurrence; these patients require rigorous follow up throughout their

Correspondence :Kumar R

Email : rajeev02@gmail.com life span and may need repeated radiation exposure.

In the last two decades, management of both adult and paediatric upper tract stones has evolved rapidly. Since the advent of extracorporeal shock wave lithotripsy (SWL) in 1980s, open surgery has progressively declined and is now limited for few indications. While SWL is preferred treatment for upper tract stones in the paediatric population, its limitations are its lower efficacy for large and multiples stones, potential long term detrimental effects on paediatric kidneys, and requirement of multiple sessions under anesthesia [4].

PCNL replaced SWL as the treatment of choice for large renal stones in adults because it provided better stone free rate in fewer treatment sessions with lower requirement of ancillary procedures. Woodside et al [5] reported the first paediatric PCNL in 1985, which included 7 patients with a mean age of 14 years. PCNL technique and armamentarium developed over the years and it is now a well-established minimally invasive procedure for renal stones in paediatric population. PCNL, however, continues to be a relatively blind procedure and there were fears of using it in children because of concerns regarding haematuria, sepsis, parenchymal injury with adult instruments and lack of data on the long term effects of PCNL on developing kidneys. In the present era, with technological advancements, miniaturization of PCNL instruments and refinements in endourological procedures there is increasing literature on the use of PCNL in paediatric patients.

\section{Concerns in paediatric patients}

PCNL addresses some of the most important concerns with stone management in children. Children need complete stone clearance in minimal procedures. The potential harmful effects of radiation in children are well known [6]. PCNL, with a single procedure, possible under ultrasound guidance can help minimize 
this. In the Asian region, patients often come from long distances with limited resources. It is essential to provide clearance in minimal number of procedures; they cannot afford repeated SWL sessions.

\section{Indications}

There are no guidelines in the literature regarding indications of PCNL in the paediatric population. It is generally believed that paediatric stones would behave similar to adult ones and urologists would follow the same indications in paediatric patients as that of adults. These include stones more than $2 \mathrm{~cm}$ in the largest dimension, failed SWL, stones resistant to SWL i.e. cysteine stones, and large upper ureteric stones [7].

\section{Access techniques}

Fluoroscopy and ultrasonography are the most commonly employed techniques for antegrade access into the pelvicalyceal system (PCS). The routine use of fluoroscopy in other urological procedures makes this the most common access technique. There are concerns regarding radiation exposure during puncture and dilatation in paediatric patients. Stratton et al [8] reviewed the effects of radiation on paediatric patients and concluded that a single abdomen computed tomography (CT) scan in a 1 year child can result in 1 CT related death per 550 scans. In 1999 Desai et al [9] reported USG guided puncture in 40 patients. The advantages of USG puncture, in addition to radiation free approach, are 3 dimensional orientation of PCS, less adjacent organ injury, lack of need of contrast and visualization of radiolucent stones. Penbegul et al [10] performed USG guided puncture in 17 patients, but fluoroscopy was used during tract dilatation. They distended the pelvis with saline through a ureteral catheter in undistended systems. Mean operative time was $67.9 \pm 14.58$ minutes (range 45-95). Fluoroscopy time was limited to $17.76 \pm 15.5$ seconds (1-54). However, current fluoroscopic machines allow better collimation of the $\mathrm{X}$-ray beam and the use of led-shields minimizes radiation exposure. The use of pulsed fluoroscopy and surgeon operated fluoroscopes further limit exposure, making this a safe procedure.

\section{Use of adult / paediatric instruments}

Another concern with paediatric PCNL is the use of adult equipment for the smaller kidneys. The concerns relate to parenchymal injury because developing kidneys are small, mobile and have friable parenchyma and small PCS [11]. This concern has led to the development of progressively smaller scopes.
The use of smaller scopes requires additional investments by the hospital and possibly greater operating time as the stone fragments have to made smaller for extraction. Traxer et al [12] evaluated the impact of tract size and concluded that it did not impact the extent of renal parenchymal injury. Bilen et al [13] used adult instruments via a 26 Fr tract $(n=23)$, pediatric instruments via a $20 \mathrm{Fr}$ tract $(\mathrm{n}=13)$ and minimal access sheath $14 \mathrm{Fr}(\mathrm{n}=10)$. They concluded that stone free rate and operative time was almost same in all the groups, but blood transfusion was higher in first 2 groups. Dogan et al [14] reported their experience in 18 patients using 20-30 Fr sheath and concluded that in children with higher stone burden, adult instruments can be used without complications. However, in their series, 4 (22\%) patients required transfusion, 3 had saline extravasation; procedure was aborted in all these 3 patients. Aron et al [15] performed PCNL in 19 pre-school children using $24 \mathrm{Fr}$ sheath and $19 \mathrm{Fr}$ nephroscope. Their stone-free rate was $94 \%$ and $5 \%$ required blood transfusion.

However, other studies shown a higher incidence of complications with adult instruments.[16,17] Zeren et al [16] reported their experience with adult instruments and concluded that while stone clearance rate was $96 \%$, blood transfusion rate was $23.9 \%$. They found a correlation between intraoperative blood loss, operative time and sheath size. Desai et al $[18,19]$ suggested that intraoperative complications increase with caliber of instruments and number of tracts in children. Jackman et al [20] described a 'mini-perc' technique using a $11 \mathrm{Fr}$ peel away vascular sheath in 1998 and found that the advantages of small size sheath were a smaller skin incision, single-step dilation and sheath placement, good working access for paediatric instruments, lower cost, less trauma so less pain, and lower incidence of complications like bleeding and possibility of doing tubeless procedures. However, we reported our experience using $24 \mathrm{Fr}$ tracts in 9 patients and $30 \mathrm{Fr}$ in 3 cases [21]. Eleven of our 12 pediatric patients had complete clearance, only one patient had postoperative fever and one had abdominal collection, which was managed conservatively.

Unsal et al [22] categorized patients in 2 groups - group $1-\leq 7$ years, group 2 with children 8-16 years. Group 2 was subdivided into group $2 \mathrm{a}$-using paediatric instruments, group 2b- using adult sized instruments. They found that intraoperative bleeding and blood transfusion was more in group $2 \mathrm{~b}$ patients in which they used adult instruments. They concluded that in 
preschool children, specific instruments for that age are required and in older children, if collecting system is dilated, then adult instruments can be used safely. PCNL with 12-18 Fr access sheath was effective and safe and did not increase the operative time and eliminated the disadvantages of adult instruments. Similarly Yan et al 23 performed PCNL on 22 renal units of 15 patients (5-14 years) using 12 -16 Fr peel away sheath. They used $9.8 \mathrm{Fr}$ ureteroscope and pneumatic lithoclast. Their overall clearance was $91 \%$ with no patient requiring blood transfusion. Similarly Mahmud et al [3] had 6\% complication rate using 17 Frnephroscopes.

The Clinical Research Office of the Endourological Society (CROES) Study on PCNL was conducted from November 2007 to December 2009 and included 96 centers worldwide [24]. They reviewed 5800 patients including 107 children aged $\leq 14$ years who had PCNL procedure. Outcomes were compared according to age group. They reported that the mean sheath size and nephrostomy tube size were larger in school-age children than the preschool children.. Guven et al [25] used paediatric or adult instruments in 60 and 80 patients respectively. They found that stone clearance rate was comparable in both the groups but blood loss was more in adult instruments group. It thus seems prudent that smaller instruments should be used where available and indicated based on the child's age, physical size and anatomy of the stone and PCS.

\section{Superior calyceal / supracostal punctures}

A good initial puncture is the cornerstone of a successful PCNL procedure. While some amount of planning is done preoperatively, the final decision is usually taken intraoperatively. The calyx should be chosen based on the location of stone and calyceal anatomy. An ideal puncture should allow direct access to the stone through a fornix of the calyx. This often happens to be the superior calyx. Superior calyx accesses are associated with a greater potential for complications as a number of these will breach the pleura. We, however, recommend a liberal use of the superior calyceal puncture in cases where it seems to provide the best access [26]. This approach is suitable for stones in superior calyx, staghorn stones, pelvis and upper ureteral stones. It has the advantage of minimal manipulation of instruments. This results in less torqueing and bleeding, a clearer vision and the possibility of universalization of the guide wire. We performed a superior calyceal puncture in 14 renal units of 13 children and compared it with 13 children who had non-superior calyceal puncture. 13 of the 14 superior calyceal punctures were supracostal. Complete clearance was achieved in all but one patient in each group. Only one patient had hydrothorax following supracostal puncture. We also reported our experience of PCNL in staghorn stones in children [20] In 12 children with staghorn stones, a superior calyceal access was chosen in 5 including 4 supracostal punctures. Complete clearance was achieved in all patients with no associated morbidity.

The incidence of chest complications following supracostal punctures is $12.5 \%$ in adult series [27,28] Most of these are asymptomatic and only 3-4\% require intervention. El-Nahas et al [29] did supracostal punctures in 20 children, there were no intrathoracic complications, and they suggested that supracostal approach should be used whenever it is indicated. To avoid pleural complications, the puncture should be placed over the lateral portion of rib during steady, quiet breathing and supra 11th-rib punctures should be avoided.

\section{Outcomes}

Stone free rates following PCNL in paediatric patients range from $58-95 \%$ (Table 1). Veeratterapillary et al [30] performed PCNL in 32 renal units in 31 patients with mean stone diameter of $19 \mathrm{~mm}$. Twenty-six required single puncture and six required multiple tracts. Eleven patients had staghorn stones. Overall clearance was achieved in 91\% including SWL in 2 patients. None required blood transfusion. In the CROES Study [24], the mean operative time was 97.02 minutes, stone free rate was $70.1 \%$ and transfusion rate was $9 \%$. Outcomes and complications rates in paediatric patients were comparable to adults in the presence of appropriate equipment and surgical experience. Caione et al [31] reported their experience of PCNL in 33 patients with mean age of 13.4 years (19 months-18 years). Stone clearance was $74 \%$ after single treatment and increased to $88 \%$ after secondary SWL. Blood transfusion was required in $16 \%$ cases. Boormans et al [32], in stones with mean size $6.0 \mathrm{~cm}^{2}$, found primary stone free rate of $58 \%$ following PCNL which increased to $81 \%$ after treating residual fragments. Similarly, El-nahas et al [29] reported clearance rate of $77 \%$ after PCNL which increased to 92.5\% after SWL.

Our clearance rate from PCNL in 12 paediatric staghorn stones was $90 \%$ [20]. In our review of 95 paediatric PCNLs in the last 10 years, we found that $83 \%$ patients were stone free after first PCNL; this increased to $94 \%$ after second-look PCNL and 
auxiliary procedures [33].

\section{Tubeless PCNL}

The safety and efficacy of tubeless PCNL (without a nephrostomy tube/ stent or both) has been widely reported in adults[35,36]. In children, there is scarcity of data regarding tubeless PCNL. While all the studies of tubeless PCNL in children concluded that there was less requirement of analgesia and shorter hospital stay following tubeless PCNL, the decision should be taken intraoperatively and depends upon the surgeon's experience [37-38]. Guven et al [25] reported tubeless PCNL in 29 children and totally tubeless in 14 . They concluded that tubeless/totally tubeless PCNL is safe and effective in paediatric stones.

\section{Complications}

Complications following PCNL in children are similar to those in adults. These include bleeding requiring blood transfusion, transient fever, systemic inflammatory response syndrome, septic shock, hypothermia, pseudo aneurysm requiring angioembolisation and chest complications.

In the adult population, complications rates according to the Clavien classification are $29 \%-44 \%[39,40]$. In 140 paediatric patients, Guven et al [39] found the overall complications rate to be $29.1 \%$. The authors felt that complications in children may be lower than in adults because these cases were performed very meticulously by well-experienced surgeons. They divided the patients according to their age i.e. infants and toddlers (group 1), preschool children (group 2) and school children (group 3) and measured perioperative complications using modified Clavien [41] classification system. Grade 1 complications occurred in 17 patients, grade 2 in 4 , grade $3 a$ in 11 and
$3 b$ in 7 . There were no grade $4-5$ complications. In complex renal stone, $19.5 \%$ required blood transfusion. There was no significant age-group specific difference in stone clearance rate, complication rate, and fall in haemoglobin.

Dogan et al [14] emphasized the risk of hypothermia in children. However, in their series, hypothermia did not occur in any of their 18 patients. Hypothermia may cause impaired coagulation, decreased drug metabolism and difficulty during reversing the patient from anaesthesia [6]. The temperature of operation theatre should be kept warm, hot lines, warm irrigation fluid and proper water seal draping of the child should be used. Zeren et al [16] reported a $24 \%$ blood transfusion requirement. They correlated this with operative time, stone burden and sheath size. In our experience of 95 cases, $15.68 \%$ had grade 1 (fever), 2 had perinephric collection and 2 had sepsis. $8.82 \%$ required blood transfusion. 3 cases had hydrothorax in supracostal punctures [33].

Data on long term effects of PCNL on paediatric kidney is lacking, but Dwaba et al [42] followed the children for 6-72 months (mean $40 \pm 10$ months) with serial technetium dimercapto-succinic acid scans for renal scarring and technetium diethylenetetraminepentaacetic acid for glomerular filteration rate (GFR). They found no new renal scarring and improvement in GFR on serial follow up following PCNL.

\section{Retrograde intrarenal surgery / mini-percutaneous nephrolithotomy}

Recently, several studies have shown feasibility of retrograde intrarenal surgery (RIRS) in larger renal stones which would otherwise be an indication for

\begin{tabular}{|c|c|c|c|c|c|c|c|}
\hline S.No. & Authors & $\begin{array}{c}\text { No. of } \\
\text { children/No. } \\
\text { of Renal } \\
\text { Units } \\
\end{array}$ & Mean Age & $\begin{array}{c}\text { Mean } \\
\text { stone } \\
\text { size }\end{array}$ & $\begin{array}{c}\text { Sheath } \\
\text { size used } \\
\text { (Fr) }\end{array}$ & \begin{tabular}{|c|} 
Stone \\
free rate
\end{tabular} & $\begin{array}{c}\text { Blood } \\
\text { transfusion } \\
\text { rate }(\%)\end{array}$ \\
\hline 1 & Veeratterapillay et $\mathrm{al}^{30}$ & $31 / 32$ & 10.8 & $19 \mathrm{~cm}$ & 28 & $84 / 91$ & 0 \\
\hline 2 & Aron et al ${ }^{14}$ & $19 / 19$ & 4.2 & $972 \mathrm{~mm}^{2}$ & 24 & $89 / 94$ & 5 \\
\hline 3 & Kumar et al ${ }^{20}$ & $12 / 12$ & 11.7 & $842 \mathrm{~mm}^{2}$ & $24-30$ & $58.3 / 91.6$ & NR \\
\hline 4 & Caine $\mathrm{P}$ et $\mathrm{al}^{31}$ & $33 / 33$ & 13.4 & NR & NR & $74 / 88$ & 16 \\
\hline 5 & Boormans JL et al ${ }^{32}$ & $23 / 26$ & $1.7-16.8$ & 6 & 18 & $58 / 81$ & $3.80 \%$ \\
\hline 6 & Bhageria et al $^{33}$ & $95 / 102$ & 11.95 & NR & NR & $83 / 94$ & 9 \\
\hline 7 & Guven et $\mathrm{al}^{34}$ & $17 / 20$ & 1.8 & $19 \mathrm{~mm}$ & 28 & $95 / 95$ & 5 \\
\hline
\end{tabular}

Table 1: Comparison of paediatric percutaneous nephrolithtomy series NR : Not reported. 
PCNL $[43,44]$. There is paucity of data regarding RIRS in children for large renal stones. Unsal et al [45] reported success rate of $88 \%$ after single treatment for renal stones $11.5 \mathrm{~mm}(8-17 \mathrm{~mm})$ with no major complications in children $<7$ years. Resorlu et al [4] compared RIRS ( $\mathrm{n}=106)$ and Mini PCNL $(\mathrm{n}=95)$ for renal stones sized $10-30 \mathrm{~mm}$ in children below 17 years. They used 9.5/11.5 Fr ureteral access sheath in a few cases for RIRS. Their stone free rate was $84.2 \%$ for RIRS group and $85.8 \%$ for miniperc group. Clavien classification complications grade 1 or 2 occurred in $17 \%$ in mini-perc group and $8.4 \%$ in RIRS group. Hospital stay, radiation exposure and morbidities were more with mini-perc group. These are limited data and RIRS continues to be evaluated for the management of larger stones in children.

\section{Conclusion}

Innovations, miniaturization of instruments, and refinements in endourological techniques have made PCNL in children more safe and efficient. While adult equipment is reasonably safe and effective, in preschool children, miniature instruments may decrease complications. PCNL should be considered the treatment of choice for large renal stones in children.

\section{References}

1. Tellaloglu S, Ander H. Stones in children. Turk J Pediatr 1984;26:51-60.

2. Srivastava T, Alon US. Urolithiasis in adolescent children. Adolesc Med Clin 2005;16:87-109.

3. Mahmud M, Zaidi Z. Percutaneous nephrolithotomy in children before school age: experience of a Pakistani centre. BJU Int 2004; 94:1352-1354

4. Resorlu B, Unsal A, Tepeler A, Atis G, Tokatli $\mathrm{Z}$, Oztuna $\mathrm{D}$, et al. Comparison of retrograde intrarenal surgery and mini-percutaneous nephrolithotomy in children with moderate-size kidney stones: results of multi-institutional analysis. Urology 2012;80:519-23

5. Woodside JR, Stevens GF, Stark GL, Borden TA, Ball WS. Percutaneous stone removal in children. J Urol 1985;134:1166-1167.

6. Kara C. Re: efficiency of percutaneous nephrolithotomy in pediatric patients using adulttype instruments. Urol Res $2012 ; 40: 271-2$.
7. Turk C, Knoll T,Petrik A, Sarica K, Skolarikos A, Straub $\mathrm{M}$,et al. EAU guidelines on urolithiaisis. Eur Assoc Urol 2013:46

8. Stratton KL, Pope JC 4th, Adams MC, Brock JW 3rd, Thomas JC. Implications of ionizing radiation in the pediatric urology patient. J Urol. $2010 ; 183: 2137-42$.

9. Desai M, Ridhorkar V, Patel S, Bapat S, Desai M. Pediatric percutaneous nephrolithotomy: assessing impact of technical innovations on safety and efficacy. J Endourol 1999;13:359-64.

10.Penbegül N, Tepeler A, Sancaktutar AA, Bozkurt Y, Atar M, Yildirim K, et al. Safety and efficacy of ultrasound-guided percutaneous nephrolithotomy for treatment of urinary stone disease in children. Urology 2012;79:1015-9.

11.Kapoor R, Solanki F, Singhania P, Andankar M, Pathak HR.Safety and efficacy of percutaneous nephrolithotomy in the pediatric population. J Endourol 2008;22:637-40.

12.Traxer O, Smith TG 3rd, Pearle MS, Corwin TS, Saboorian H, Cadeddu JA. Renal parenchymal injury after standard and mini percutaneous nephrostolithotomy.J Urol 2001;165:1693-5.

13. Bilen CY, Koçak B, Kitirci G, Ozkaya O, Sarikaya S. Percutaneous nephrolithotomy in children: lessons learned in 5 years at a single institution. JUrol 2007 ; 177:1867-71.

14. Dogan B, Atmaca AF, Canda AE, Isgoren AE, Akbulut Z, Balbay MD. Efficiency of percutaneous nephrolithotomy in pediatric patients using adult-type instruments. Urol Res 2012;40:259-62.

15. Aron M, Yadav R, Goel R, Hemal AK, Gupta NP. Percutaneous nephrolithotomy for complete staghorn calculi in preschool children. J Endourol $2005 ; 19: 968-72$.

16. Zeren S, Satar N, Bayazit Y, Bayazit AK, Payasli K, Ozkeçeli R. Percutaneous nephrolithotomy in the management of pediatric renal calculi. J Endourol 2002;16:75-8.

17. Gunes A, Yahya Ugras M, Yilmaz U, Baydinc C, Soylu A. Percutaneous nephrolithotomy for pediatric stone disease--our experience with adultsized equipment. Scand J Urol Nephrol 2003;37:477-81. 
18. Desai M. Endoscopic management of stones in children. Curr Opin Urol 2005; 15:107-12.

19. Desai MR, Kukreja RA, Patel SH, Bapat SD. Percutaneous nephrolithotomy for complex pediatric renal calculus disease. J Endourol 2004 ;18:23-7.

20. Jackman SV, Hedican SP, Peters CA, Docimo SG. Percutaneous nephrolithotomy in infants and preschool age children: experience with a new technique. Urology 1998;52:697-701.

21. Kumar R, Anand A, Saxena V, Seth A, Dogra PN, Gupta NP. Safety and efficacy of PCNL for management of staghorn calculi in pediatric patients.J Pediatr Urol 2011; 7:248-51.

22. Unsal A, Resorlu B, Kara C, Bozkurt OF, Ozyuvali E.Safety and efficacy of percutaneous nephrolithotomy in infants, preschool age, and older children with different sizes of instruments. Urology $2010 ; 76: 247-52$.

23. Yan X,Li XG,Gan WD,Guo HQ. Percutaneous nephrolithotomy using uretroscope and pneumatic lithotripsy in the management of pediatric renal calculi. World J Pediatr 2007;3:146-49

24.Guven S, Frattini A, Onal B, Desai M, Montanari E, CROES PCNL Study Group, et al. Percutaneous nephrolithotomy in children in different age groups: data from the Clinical Research Office of the Endourological Society (CROES) Percutaneous Nephrolithotomy Global Study. BJU Int $2013 ; 111: 148-56$.

25. Guven S, Istanbulluoglu O, Gul U, Ozturk A, Celik H, Aygün C, et al. Successful percutaneous nephrolithotomy in children: multicenter study on current status of its use, efficacy and complications using Clavien classification. J Urol 2011;185:1419-24.

26. Anand A, Kumar R, Dogra PN, Seth A, Gupta NP. Safety and efficacy of a superior caliceal puncture in pediatric percutaneous nephrolithotomy. J Endourol 2010 ;24:1725-8.

27.Stening SG and Bourne S: Supracostal percutaneous nephrolithotomy for upper pole caliceal calculi. J Endourol 1998;12: 359-62.

28. Munver R, Delvecchio FC, Newman GE, Preminger GM. Critical analysis of supracostal access for percutaneous renal surgery. J Urol
2001; 166: 1242-6

29.El-Nahas AR, Shokeir AA, El-Kenawy MR, Shoma AM, Eraky I, El-Assmy AM, et al . Safety and efficacy of supracostal percutaneous nephrolithotomy in pediatric patients. J Urol. 2008 ; 180:676-80.

30.Veeratterapillay R, Shaw MB, Williams R, Haslam P, Lall A, De la Hunt M, et al.Safety and efficacy of percutaneous nephrolithotomy for the treatment of paediatric urolithiasis. Ann R Coll Surg Engl 2012 ;94:588-92.

31.Caione P, Matarazzo E, Battaglia S. Stone treatment in children: where we are today? Arch Ital Urol Androl 2010;82:45-8.

32.Boormans JL, Scheepe JR, Verkoelen CF, Verhagen PC. Percutaneous nephrolithotomy for treating renal calculi in children. BJU Int 2005 ;95:631-4.

33.Bhageria A, Nayak B, Seth A, Dogra PN, Kumar R. percutaneous nephrolithotomy: Single-centre 10year experience. J Pediatr Urol 2013 Mar 13. [Epub ahead of print]

34.Guven S, Istanbulluoglu O, Ozturk A, Ozturk B, Piskin M, Cicek T, et al . Percutaneous nephrolithotomy is highly efficient and safe in infants and children under 3 years of age. Urol Int 2010;85:455-60.

35. Yuan H, Zheng S, Liu L, Han P, Wang J, Wei Q. The efficacy and safety of tubeless percutaneous nephrolithotomy: a systematic review and metaanalysis. Urol Res 2011;39:401-10.

36.Gonen M, Cicek T, Ozkardes H. Tubeless and stentless percutaneous nephrolithotomy in patients requiring supracostal access.Urol Int 2009;82:440-3.

37.Khairy Salem H, Morsi HA, Omran A, Daw MA. Tubeless percutaneous nephrolithotomy in children. J Pediatr Urol 2007 ;3:235-8.

38. Samad L, Zaidi Z. Tubed vs tubeless PCNL in children. J Pak Med Assoc 2012 ;62:892-6.

39.de la Rosette JJ, Zuazu JR, Tsakiris P, Elsakka AM, Zudaire JJ, Laguna MP, et al . Prognostic factors and percutaneous nephrolithotomy morbidity: a multivariate analysis of a contemporary series using the Clavien classification. J Urol. 2008 ;180:2489-93.

40 .Tefekli A, Ali Karadag M, Tepeler K, Sari E, 
Berberoglu Y, Baykal M, et al. Classification of percutaneous nephrolithotomy complications using the modified clavien grading system: looking for a standard. Eur Urol 2008 ;53:184-90.

41. Dindo D, Demartines N, Clavien PA. Classification of surgical complications: a new pro- posal with evaluation in a cohort of 6336 patients and results of a survey. Ann Surg 2004; 240:205-13.

42. Dawaba MS, Shokeir AA, Hafez A, Shoma AM, El-Sherbiny MT, Mokhtar A, et al. Percutaneous nephrolithotomy in children: early and late anatomical and functional results. J Urol $2004 ; 172: 1078-81$.

43.Prabhakar M. Retrograde ureteroscopic intrarenal surgery for large $(1.6-3.5 \mathrm{~cm})$ upper ureteric/renal calculus.Indian J Urol 2010;26:469.

44.Bader MJ, Gratzke C, Walther S, Weidlich P, Staehler M, Seitz M, et al. Efficacy of retrograde ureteropyeloscopic holmium laser lithotripsy for intrarenal calculi $>2 \mathrm{~cm}$. Urol Res 2010;38:397402.

45.Unsal A, Resorlu B. Retrograde intrarenal surgery in infants and preschool-age children. J Pediatr Surg 2011;46:2195-2199. 